\title{
Interconnections Seam Study
}

\section{Overview}

Gregory Brinkman, Joshua Novacheck, Aaron Bloom, and James McCalley

October 2020 


\section{Disclaimer}

- This material includes unpublished preliminary data and analysis that has not been peerreviewed and is subject to change.

- The study results have been submitted to the journal IEEE Transactions in Power Systems for possible publication.

A preprint of the article has been posted to nrel.gov.

- This work was authored in part by the National Renewable Energy Laboratory, operated by Alliance for Sustainable Energy, LLC, for the U.S. Department of Energy (DOE) under Contract No. DE-AC36-08GO28308. Funding provided by the DOE Office of Energy Efficiency and Renewable Energy Wind Energy Technologies Office and the DOE Office of Electricity, in support of the Grid Modernization Initiative. The views expressed in the article do not necessarily represent the views of the DOE or the U.S. Government. The U.S. Government retains and the publisher, by accepting the article for publication, acknowledges that the U.S. Government retains a nonexclusive, paid-up, irrevocable, worldwide license to publish or reproduce the published form of this work, or allow others to do so, for U.S. Government purposes 


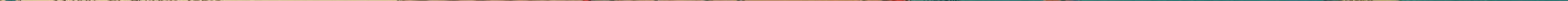




\section{Continental Transmission Studies}

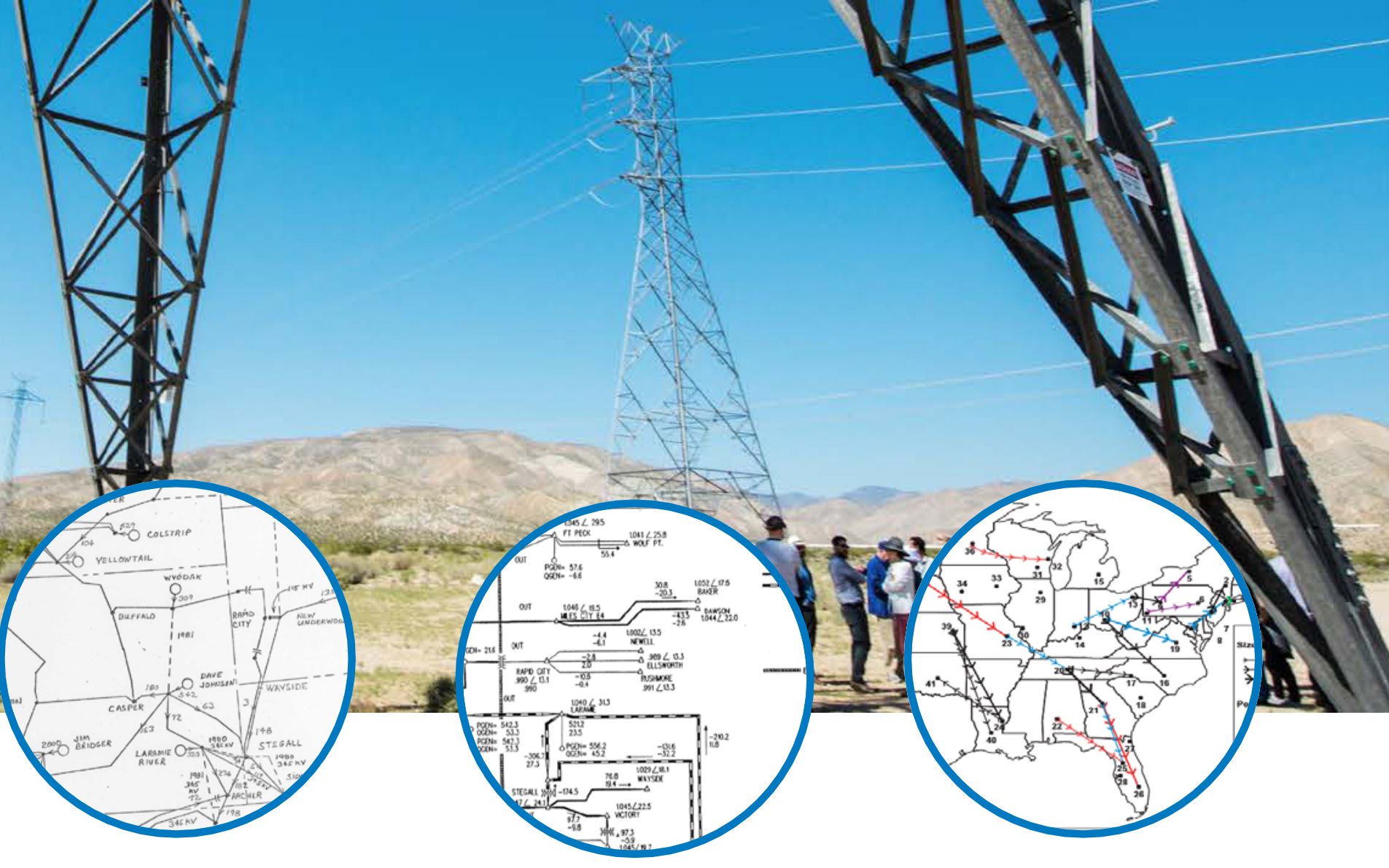

Chicago Tribune

1923

Tying the Seasons to Industry
Bureau of Reclamation

1952 Super Transmission

System
Bonneville Power Administration

1979

Interconnection of the Eastern and Western
Western Area Power Administration

1994

East/West AC Intertie Feasibility Study
U.S. Department of Energy

2002

National Transmission Study 
What about

Now? 


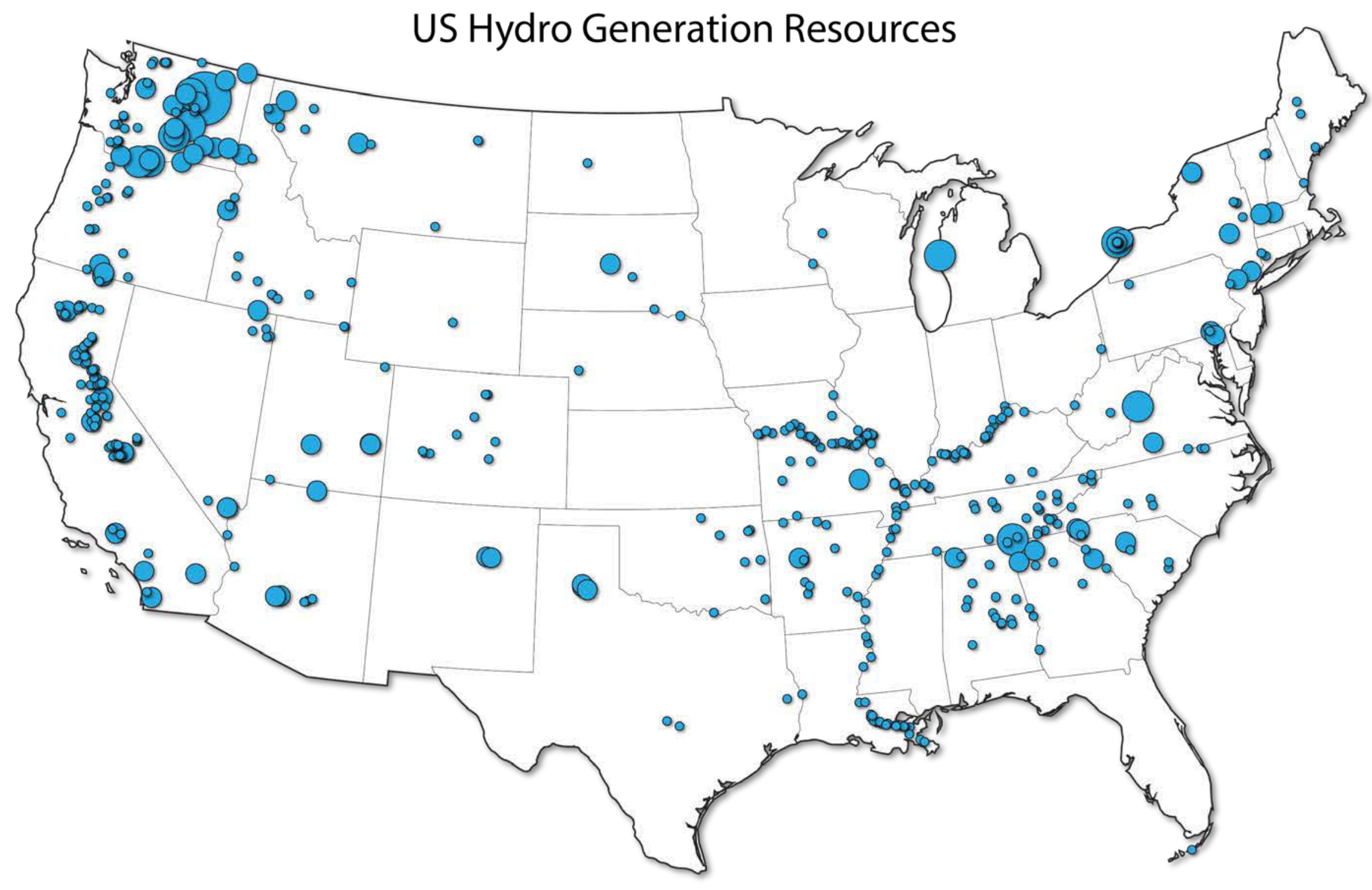




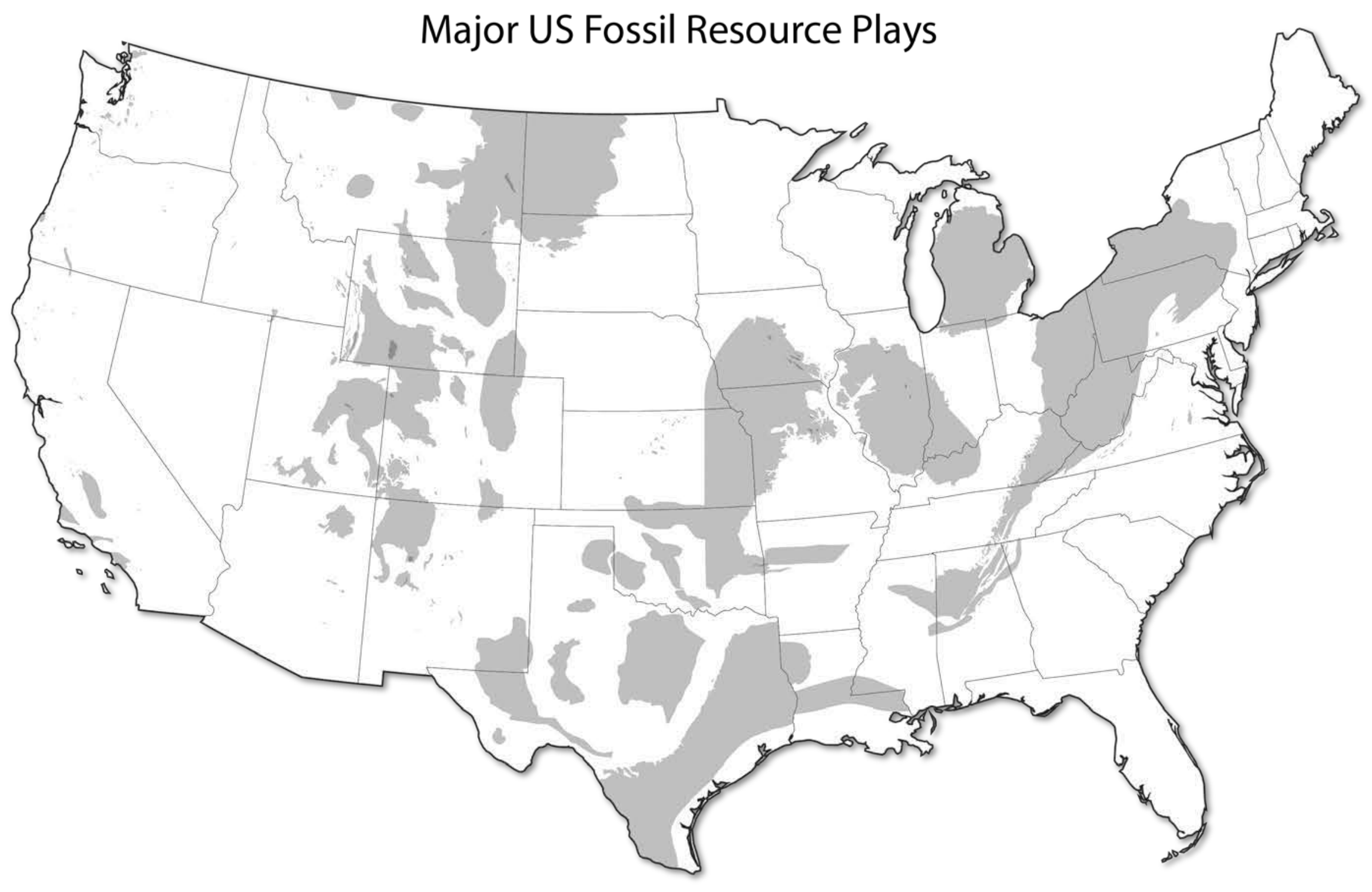




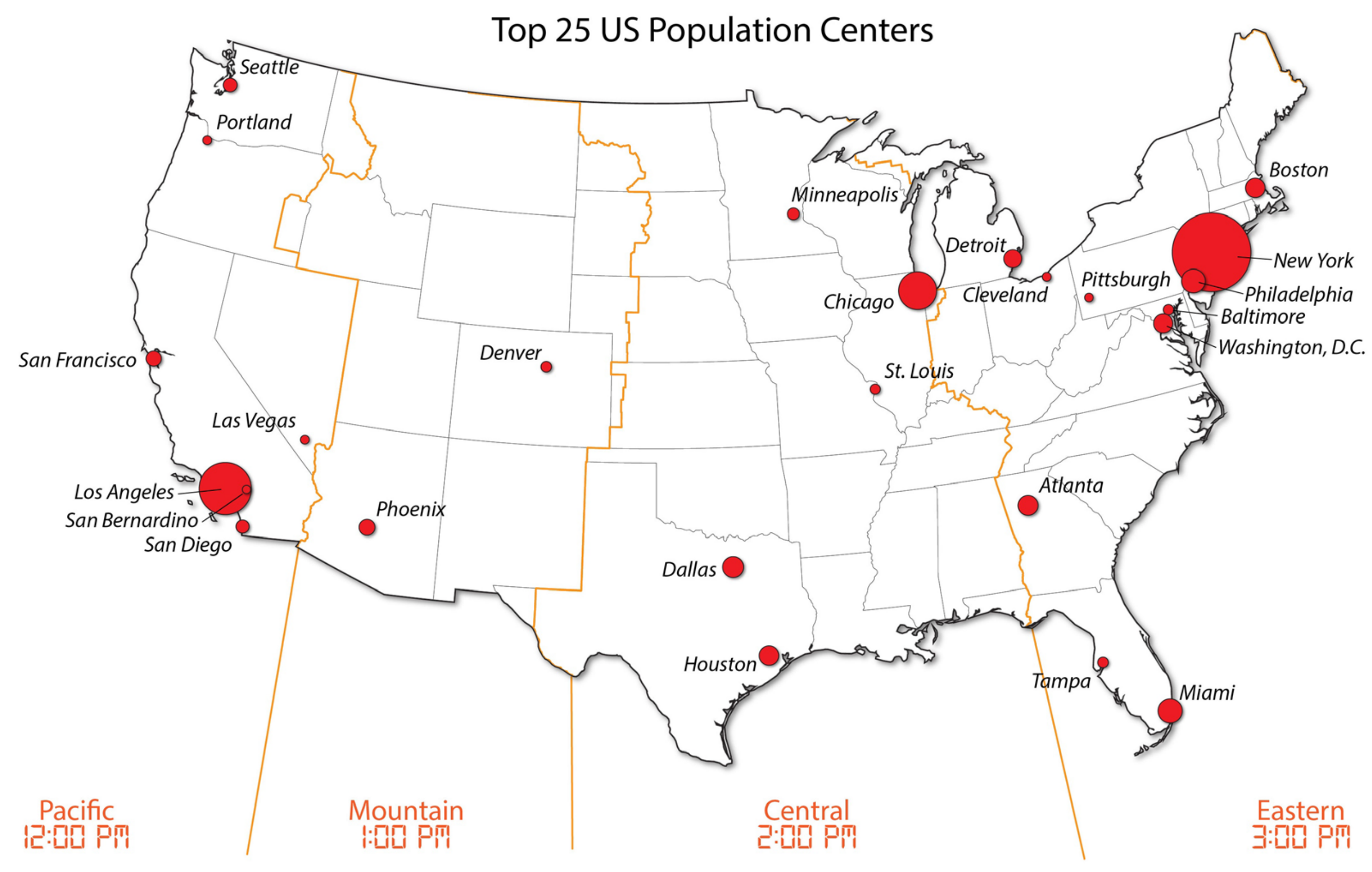




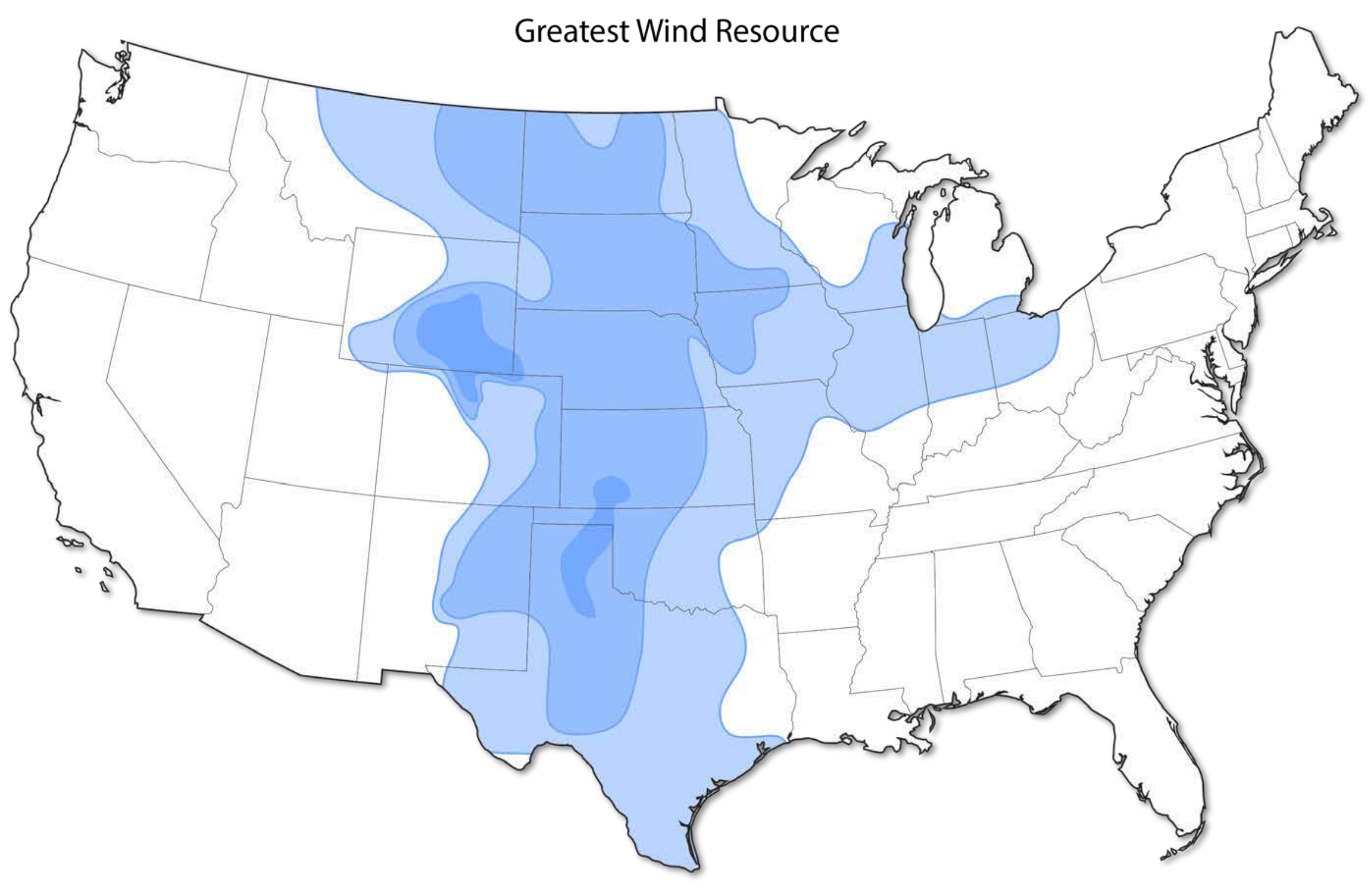




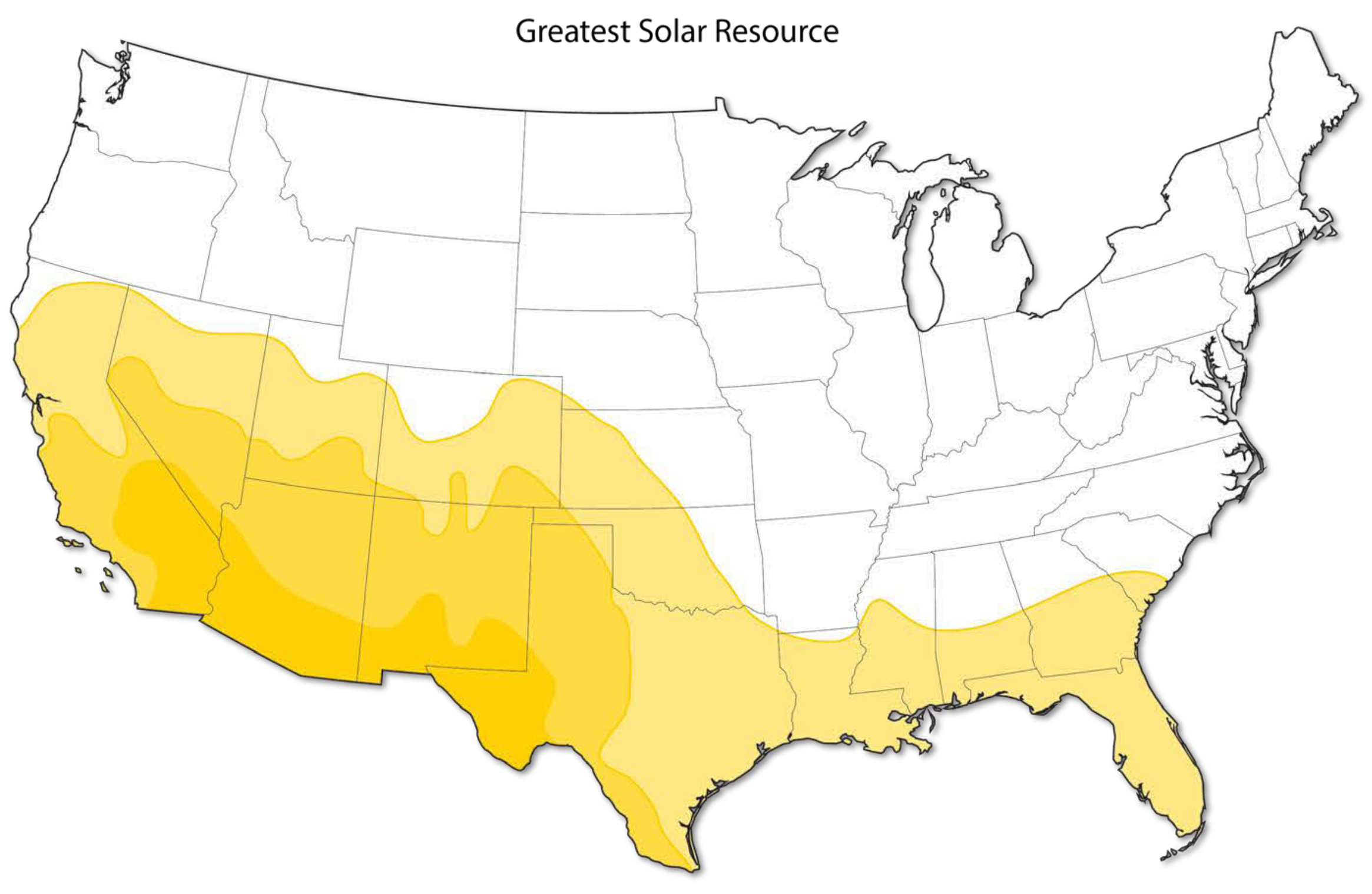




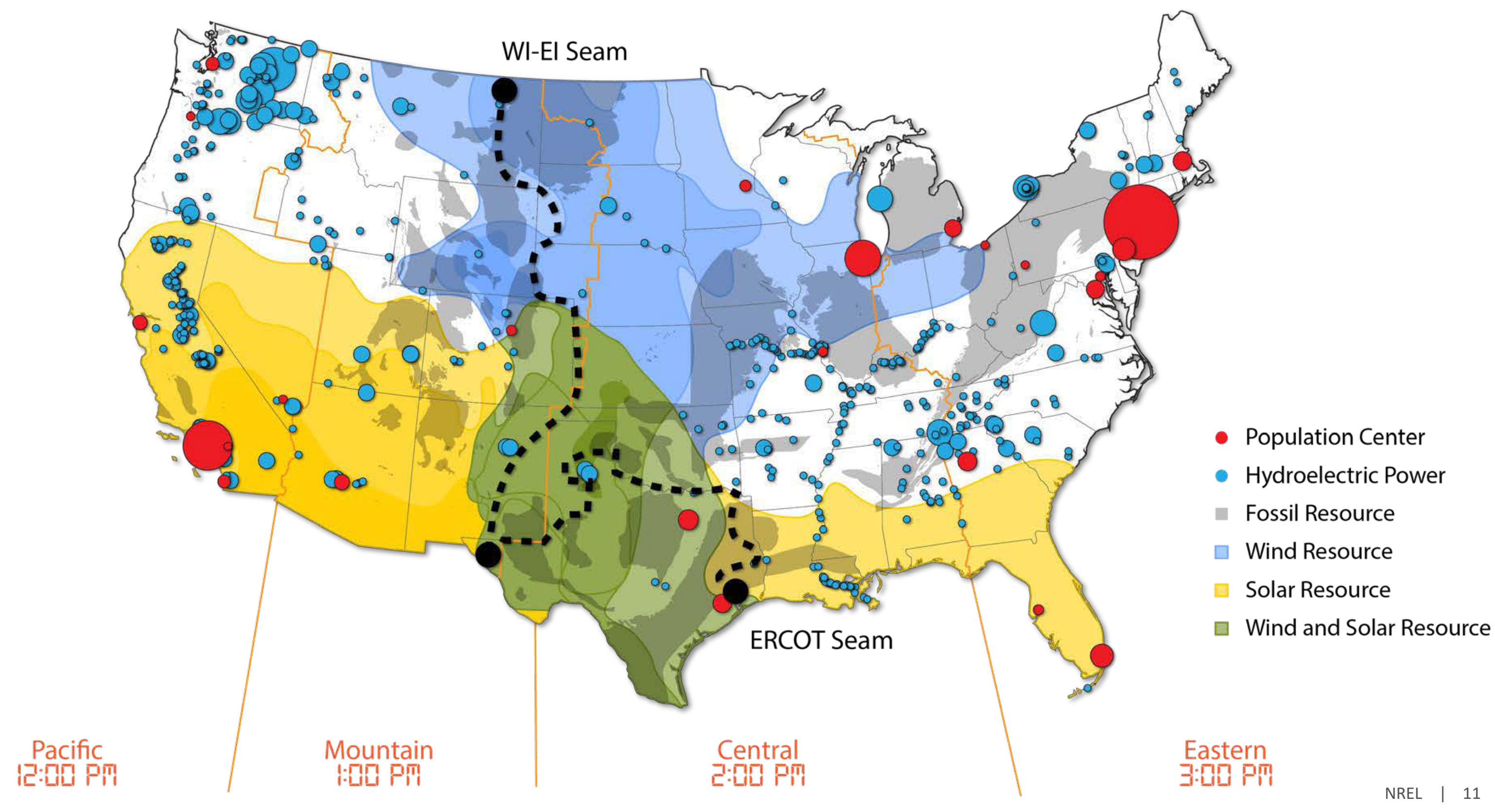




\section{Generation and Transmission Technologies}

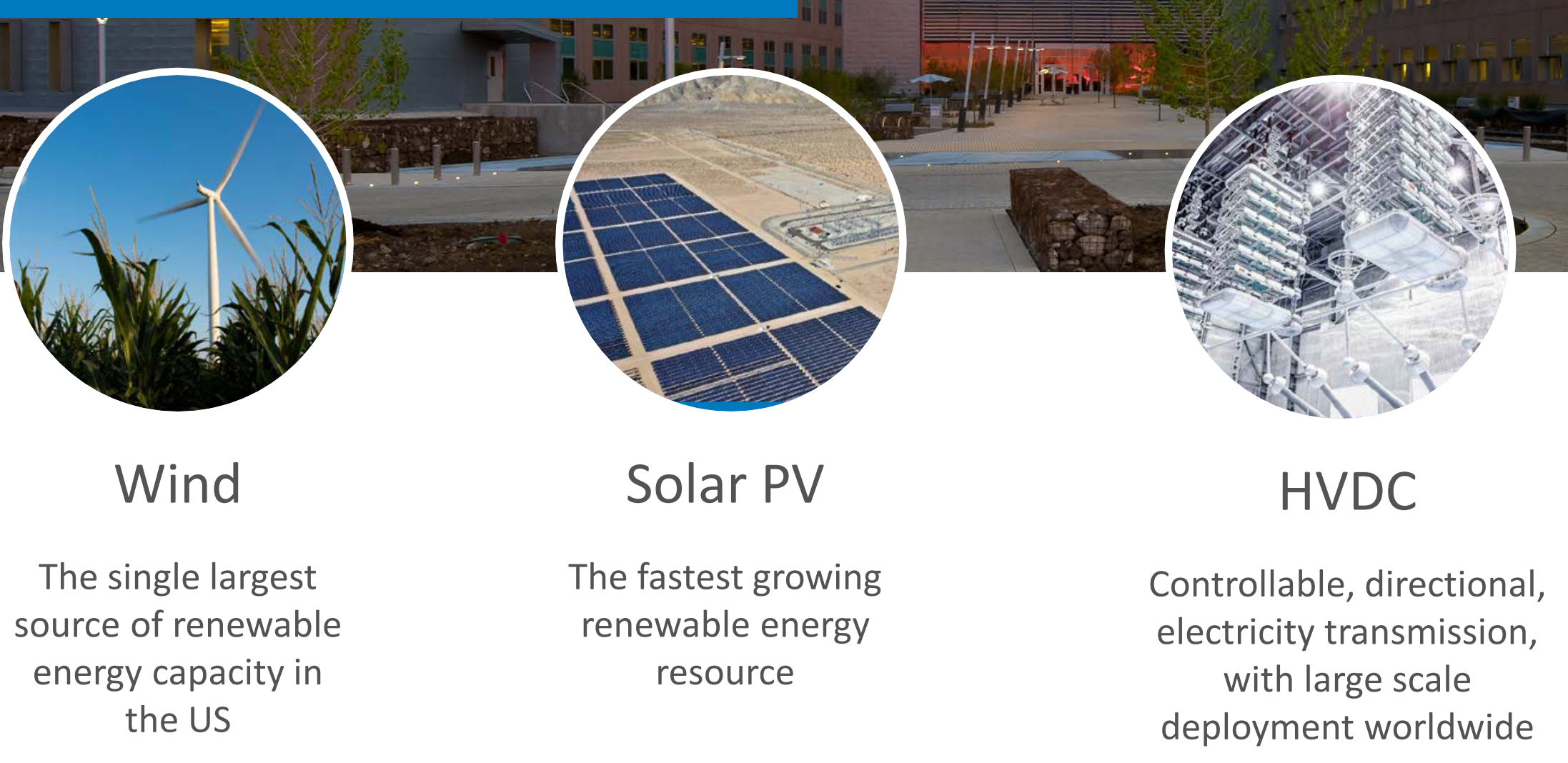




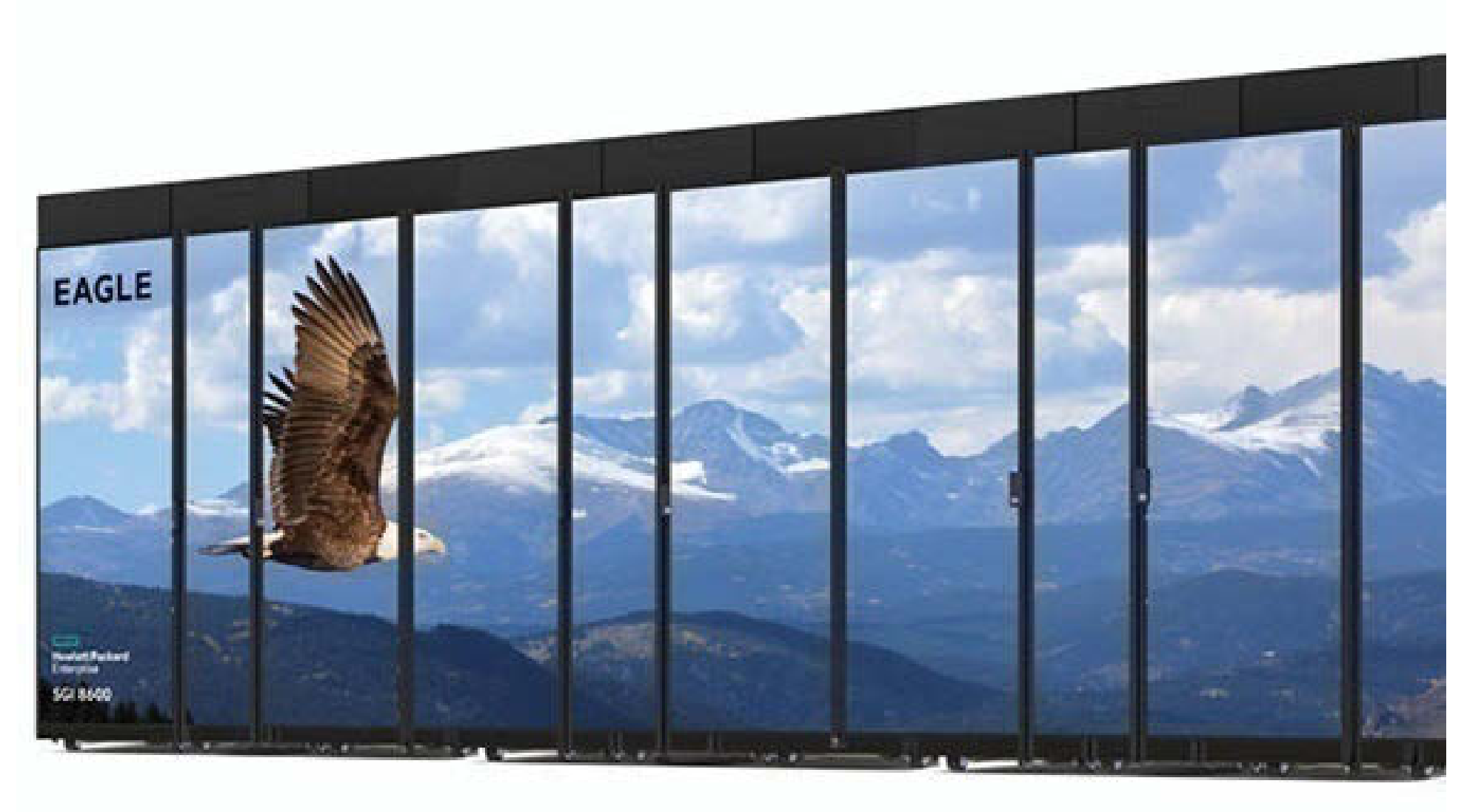

\section{New Computational Capabilities}

- Parallel computing environments, complex algorithms, and artificial intelligence offer new capabilities

- 100,000 node transmission models can be simulated for an entire year, in a single day

- The dawn of Exascale computing 


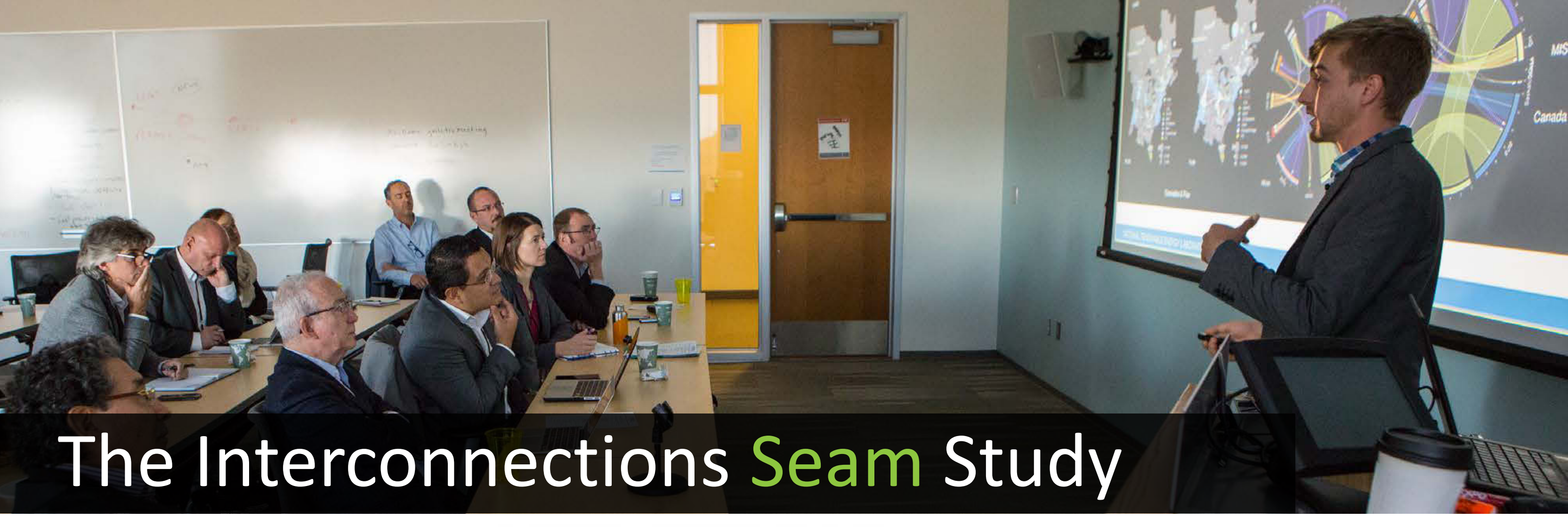

SPP Southwest

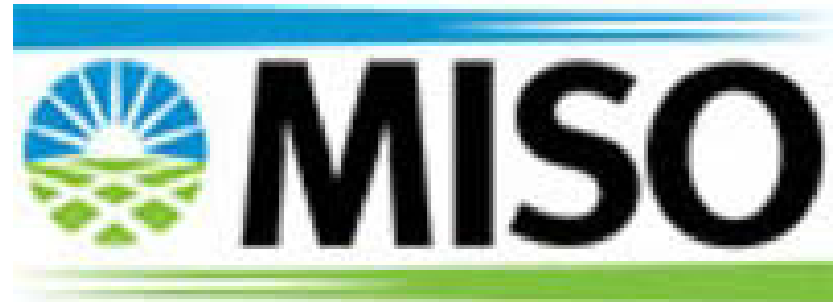

IOWA STATE UNIVERSITY
Pacific Northwest NATIONAL LABORATORY 


\section{Study Objective}

Through the Interconnections Seam Study, NREL joins national lab, university, and industry partners to evaluate the benefits and costs of options for continental transmission across the U.S. electric grid that would create a more integrated power system that could drive economic growth and increase efficient development and utilization of the nation's abundant energy resources, including solar, wind, and natural gas.

- Visit the Seam Study webpage to learn more

- View a preprint of the article submitted to IEEE Transactions in Power Systems

- View study visualization animations on YouTube 


\section{Comprehensive Economic and Resource Adequacy Analysis}

CGT-Plan (Planning/Expansion Model)

- lowa State University

- Capital and operating costs 2024-2038

- Generation and transmission system for 2038

PLEXOS (Production Cost Model)

- NREL

- $\quad$ Operating costs 2038

- Hourly unit commitment and economic dispatch

PSSE (Steady-State AC Analysis)

- PNNL

- Develop a capability for future work

- Preliminary analysis of AC power flow impacts

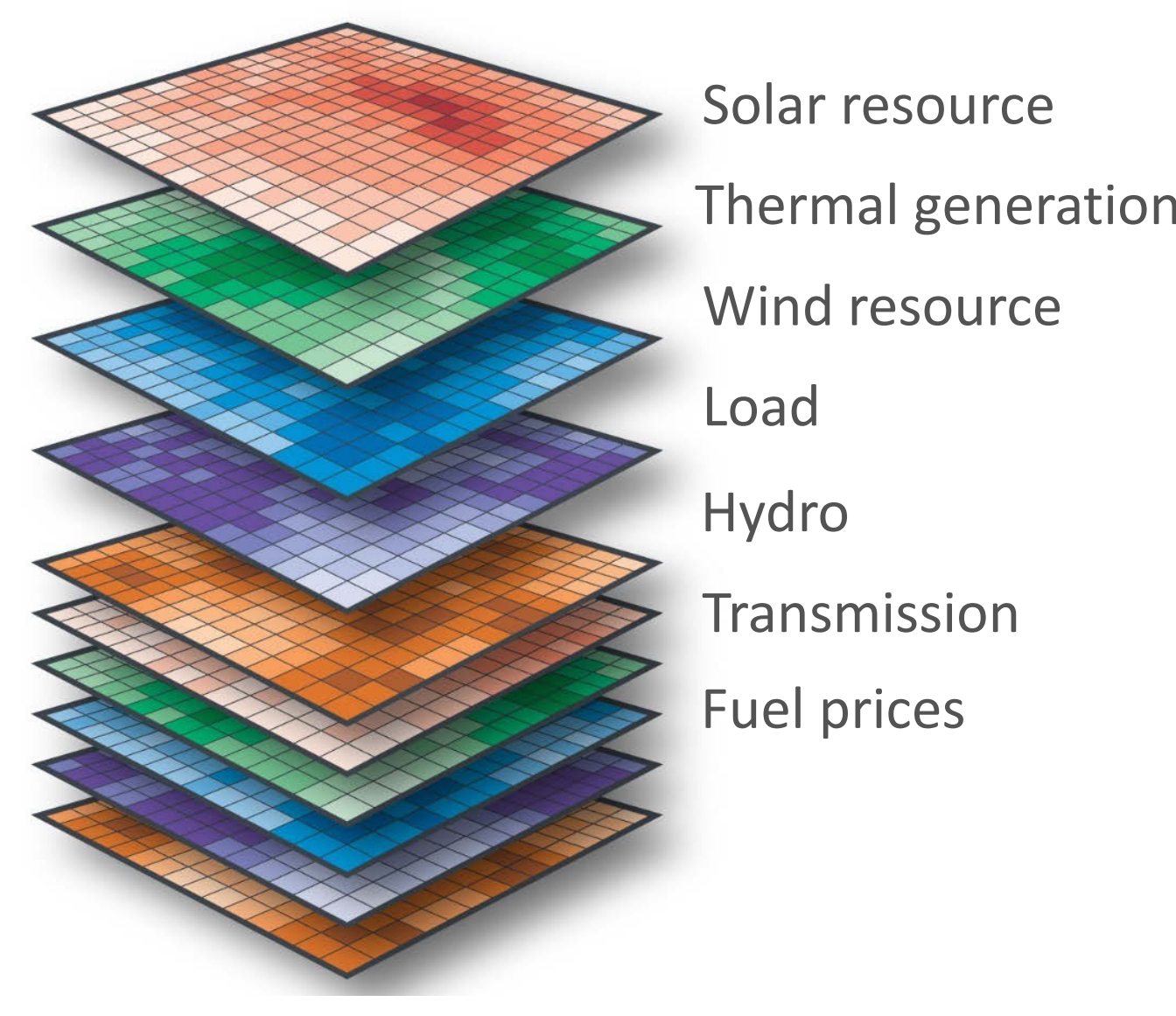




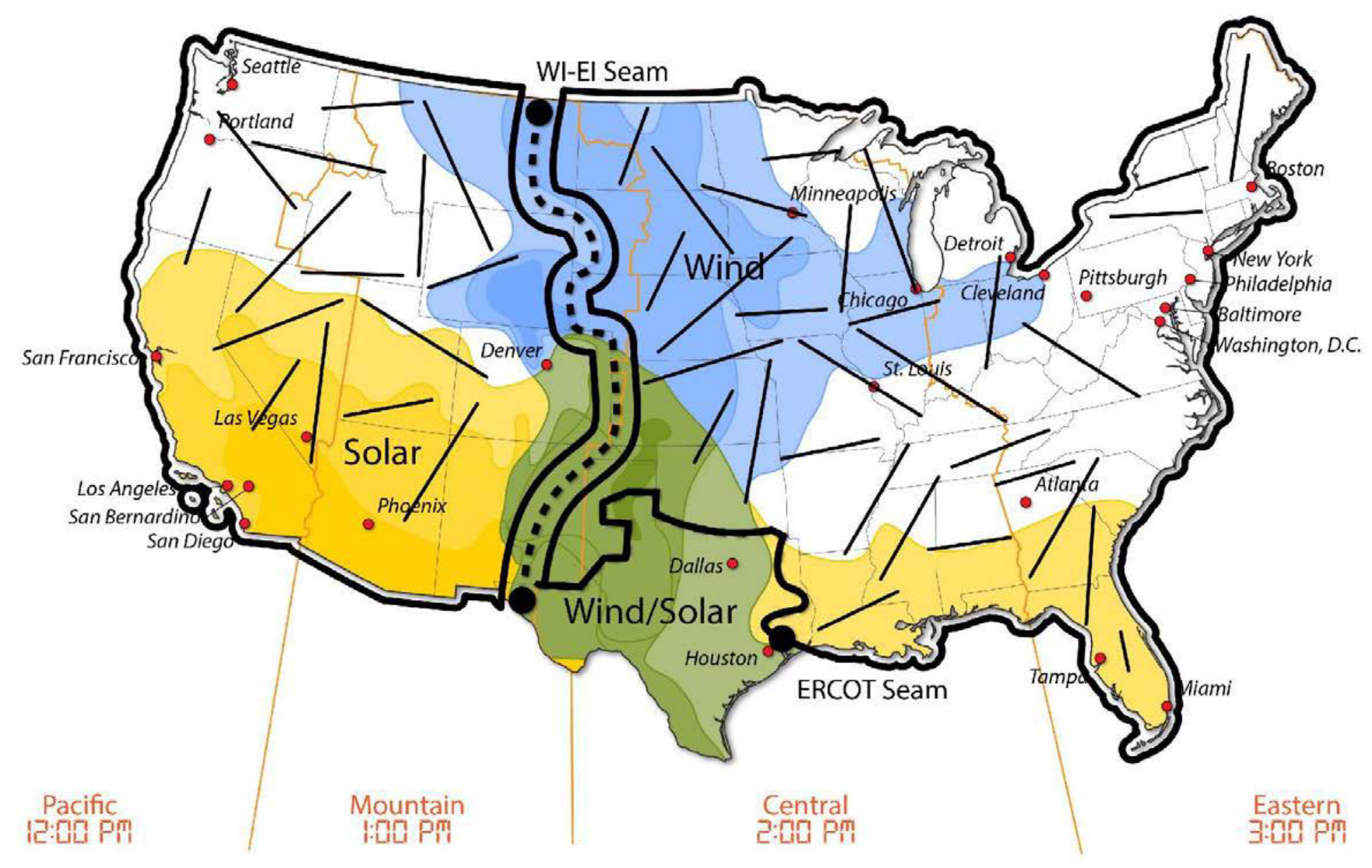

\section{Design 1 (D1)}

Existing B2B facilities are replaced at their current (2017) capacity level and new AC transmission and generation are cooptimized to minimize system-wide costs. 


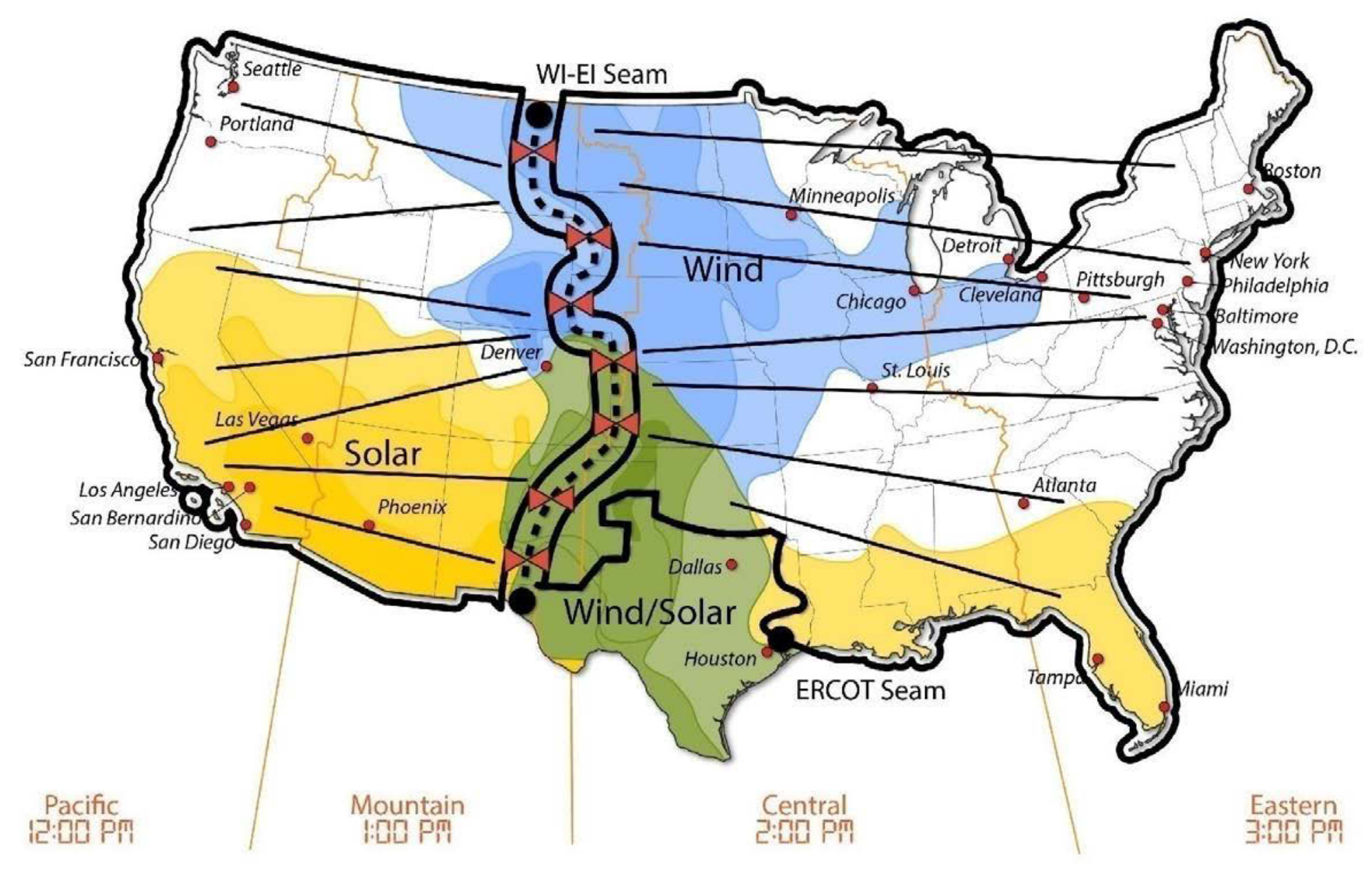

\section{Design 2a (D2a)}

Existing B2B facilities are replaced at a capacity rating that is co-optimized along with other investments in $\mathrm{AC}$ transmission and generation. 


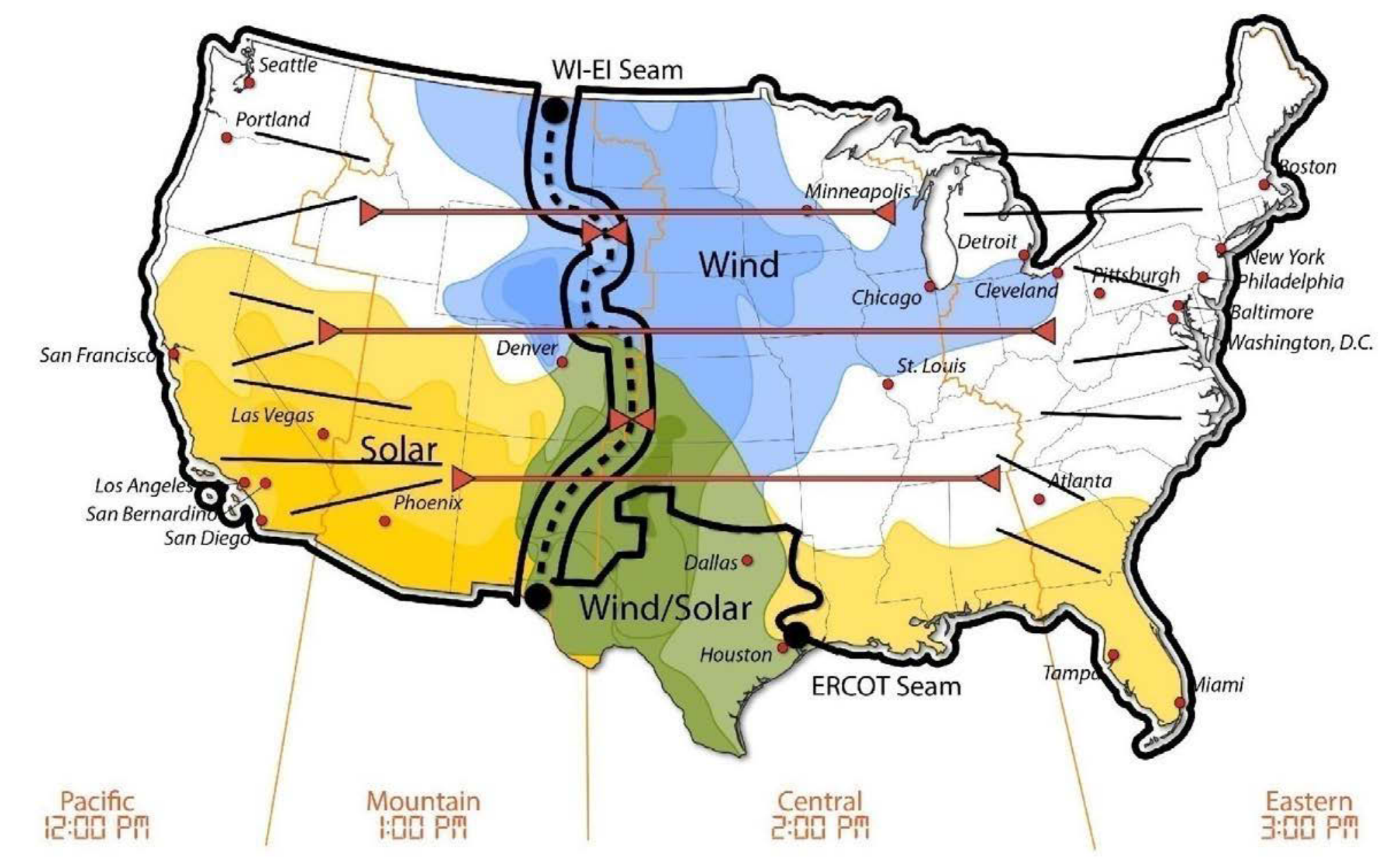

\section{Design $2 b$ (D2b)}

Three HVDC transmission segments are built between the Eastern Interconnection and Western

Interconnection and existing B2B facilities are cooptimized with other investments in AC transmission and generation. 


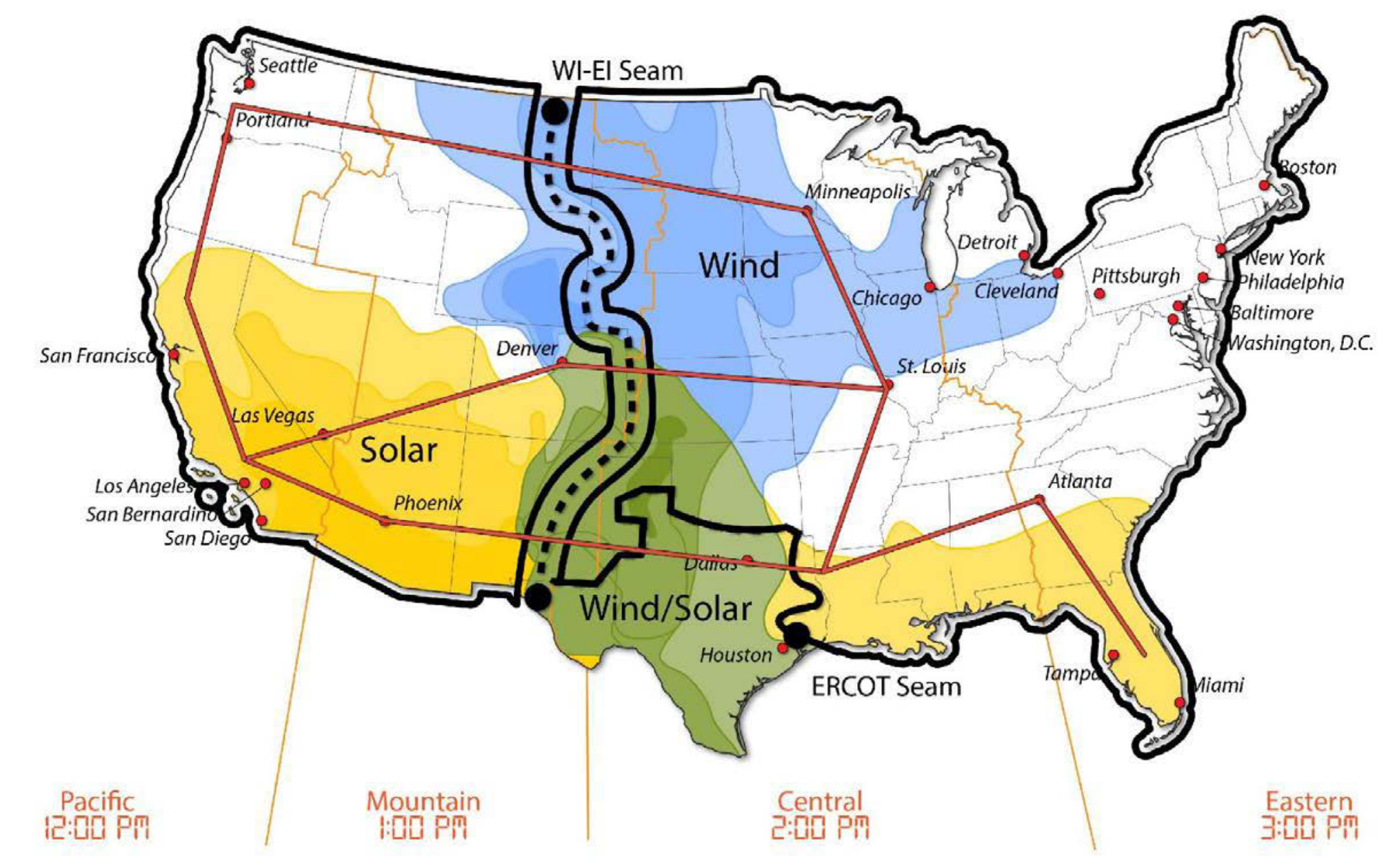

\section{Design 3 (D3)}

Macrogrid (a nationwide HVDC transmission network) is built and additional AC transmission and generation are cooptimized to minimize system costs. 


\section{Scenarios}

\begin{tabular}{|c|c|}
\hline Scenario & Key Assumption Differences \\
\hline Base Case & AEO 2017 gas price, existing state RPS laws \\
\hline Low Gas Price & $\begin{array}{l}\text { AEO } 2017 \text { High Gas Resource (gas prices regionally } \\
\text { and temporally varying around } \$ 4 / \mathrm{mmbtu} \text { ) }\end{array}$ \\
\hline High Gas Price & $\begin{array}{l}\text { AEO } 2017 \text { Low Gas Resources (gas prices varying } \\
\text { around } \$ 6 / \mathrm{mmbtu} \text { ) }\end{array}$ \\
\hline $\begin{array}{l}\text { High AC Trx Cost } \\
(1.5 x)\end{array}$ & $\begin{array}{l}50 \% \text { higher than base transmission cost. Base } \\
\text { transmission cost from [16] }\end{array}$ \\
\hline $\begin{array}{l}\text { High AC Trx Cost } \\
(2 x)\end{array}$ & Double the base transmission cost \\
\hline No Retirements & $\begin{array}{l}\text { Model does not retire any generating units beyond } \\
\text { announced retirements }\end{array}$ \\
\hline $\begin{array}{l}\text { Low-Cost } \\
\text { Renewables }\end{array}$ & ATB 2017 Low Cost projections for wind and solar \\
\hline High VG & $\begin{array}{l}\text { Least-cost generation mix when using a carbon } \\
\text { cost from } \$ 3 / \text { tonne in } 2024 \text { to } \$ 45 / \text { tonne in } \\
2038^{* *}\end{array}$ \\
\hline
\end{tabular}

- The four conceptual transmission designs were studied under eight different grid environments

- A total of 32 total capacity expansion model runs were made

- Scenarios vary in terms of technology cost, fuel price, and policy assumptions

- Refer to preprint article for numbered references

Description of the Scenarios*

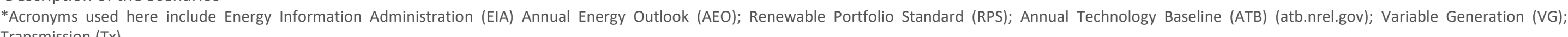

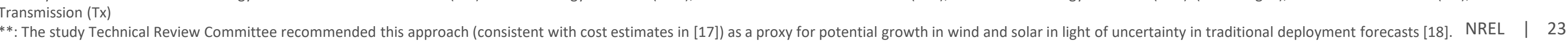



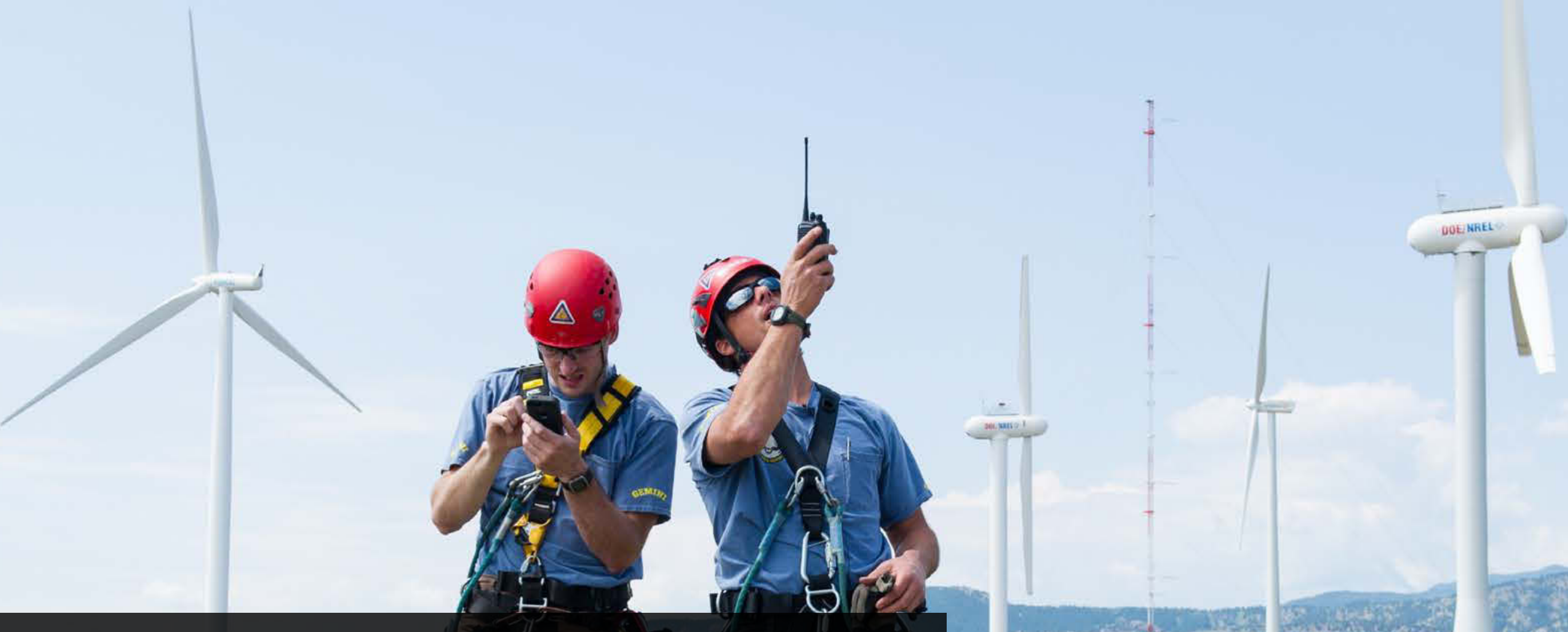

\section{System Characteristics} and Operation 
Generation Capacity for Selected Scenarios and Designs

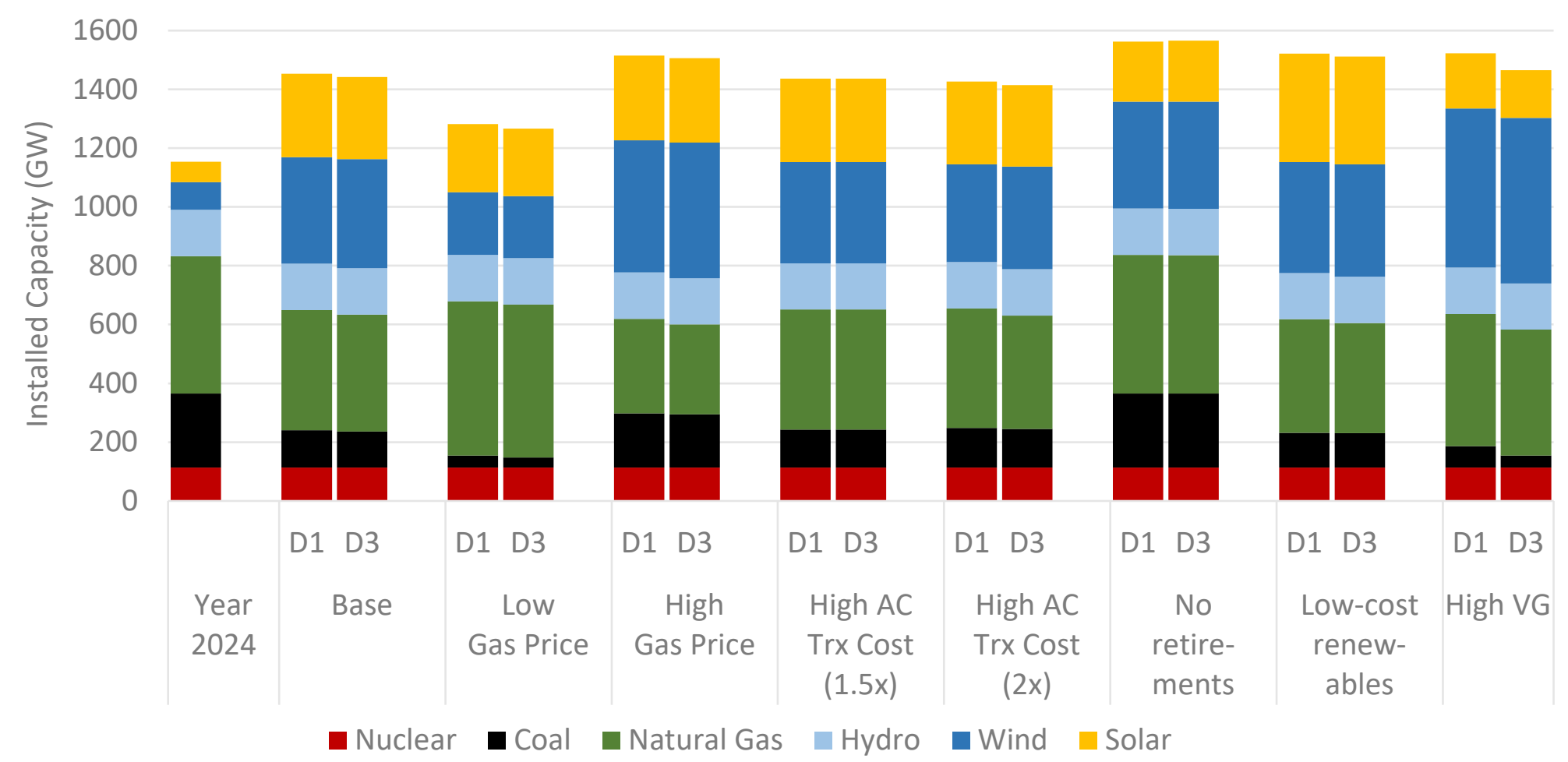

$$
\begin{aligned}
& \text { D1 = No new cross-seam transmission } \\
& \text { D2 } a=B 2 B \text { expansion } \\
& \text { D2 } b=\text { B2B expansion }+3 \text { HVDC lines } \\
& \text { D3 = HVDC Macrogrid }
\end{aligned}
$$



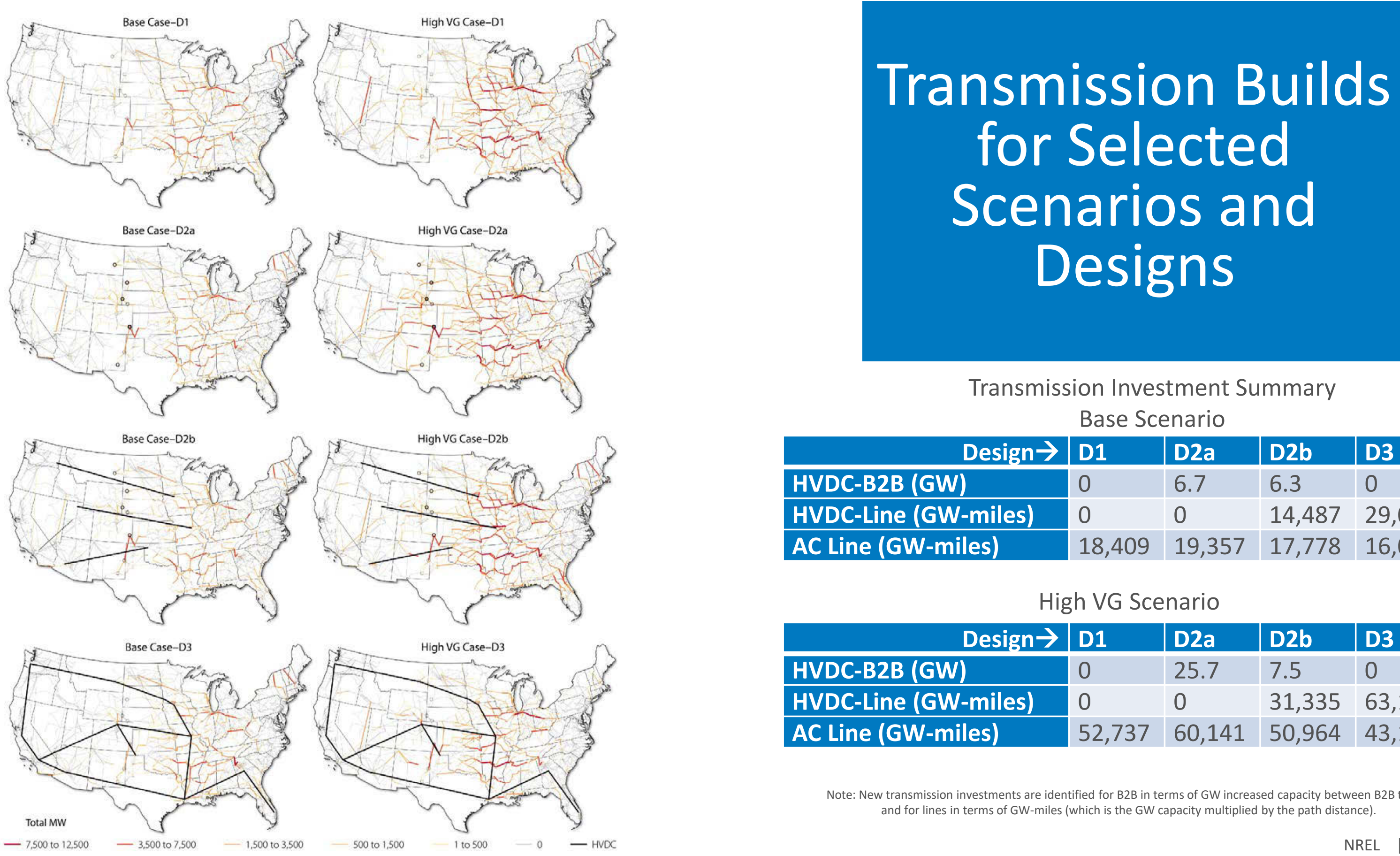

Transmission Investment Summary Base Scenario

\begin{tabular}{|l|l|l|l|l|}
\hline \multicolumn{1}{|c|}{ Design $\rightarrow$} & D1 & D2a & D2b & D3 \\
\hline HVDC-B2B (GW) & 0 & 6.7 & 6.3 & 0 \\
\hline HVDC-Line (GW-miles) & 0 & 0 & 14,487 & 29,062 \\
\hline AC Line (GW-miles) & 18,409 & 19,357 & 17,778 & 16,076 \\
\hline
\end{tabular}

High VG Scenario

\begin{tabular}{|l|l|l|l|l|}
\hline \multicolumn{1}{|c|}{ Design- } & D1 & D2a & D2b & D3 \\
\hline HVDC-B2B (GW) & 0 & 25.7 & 7.5 & 0 \\
\hline HVDC-Line (GW-miles) & 0 & 0 & 31,335 & 63,156 \\
\hline AC Line (GW-miles) & 52,737 & 60,141 & 50,964 & 43,190 \\
\hline
\end{tabular}

Note: New transmission investments are identified for B2B in terms of GW increased capacity between B2B terminals, and for lines in terms of GW-miles (which is the GW capacity multiplied by the path distance). 


\section{Annual Generation of 2038 Systems}

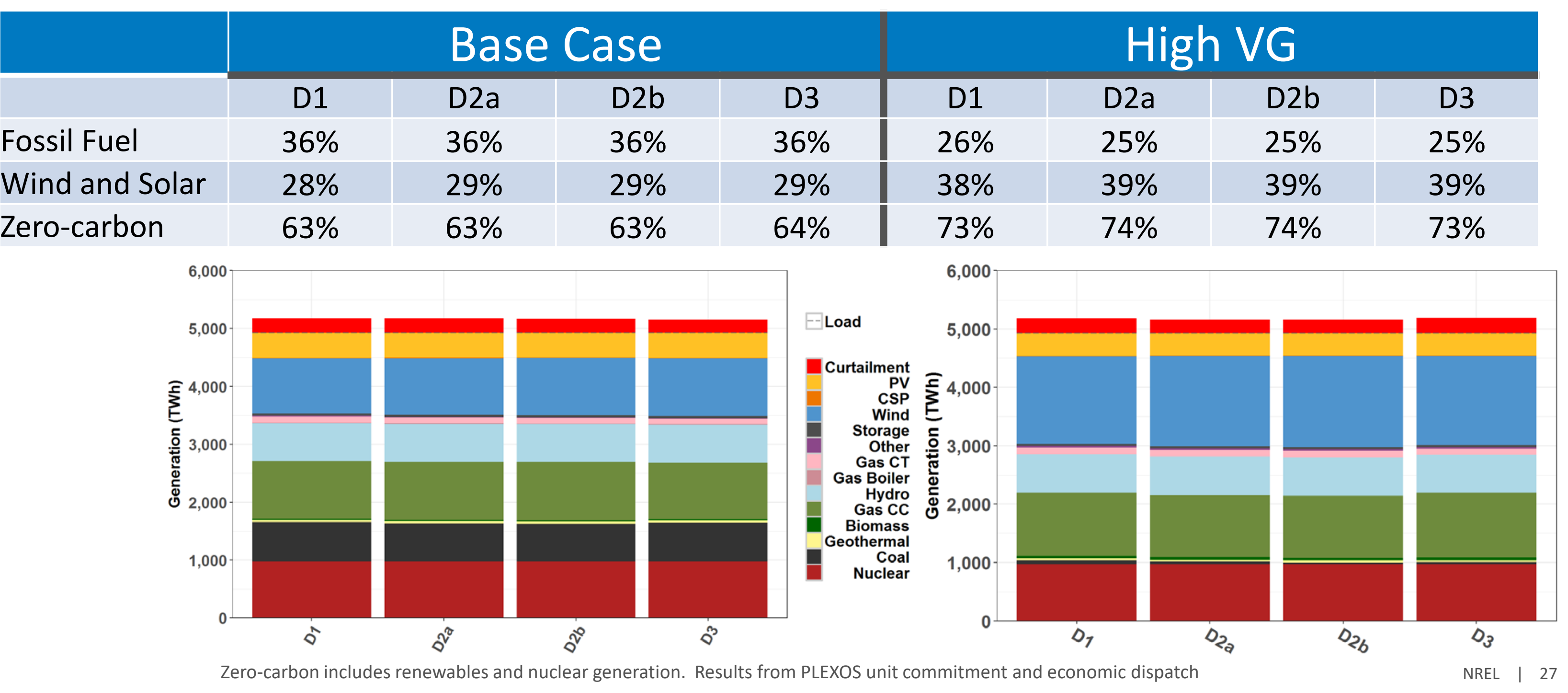




\section{Generation Difference from D1}

\section{Base Case}

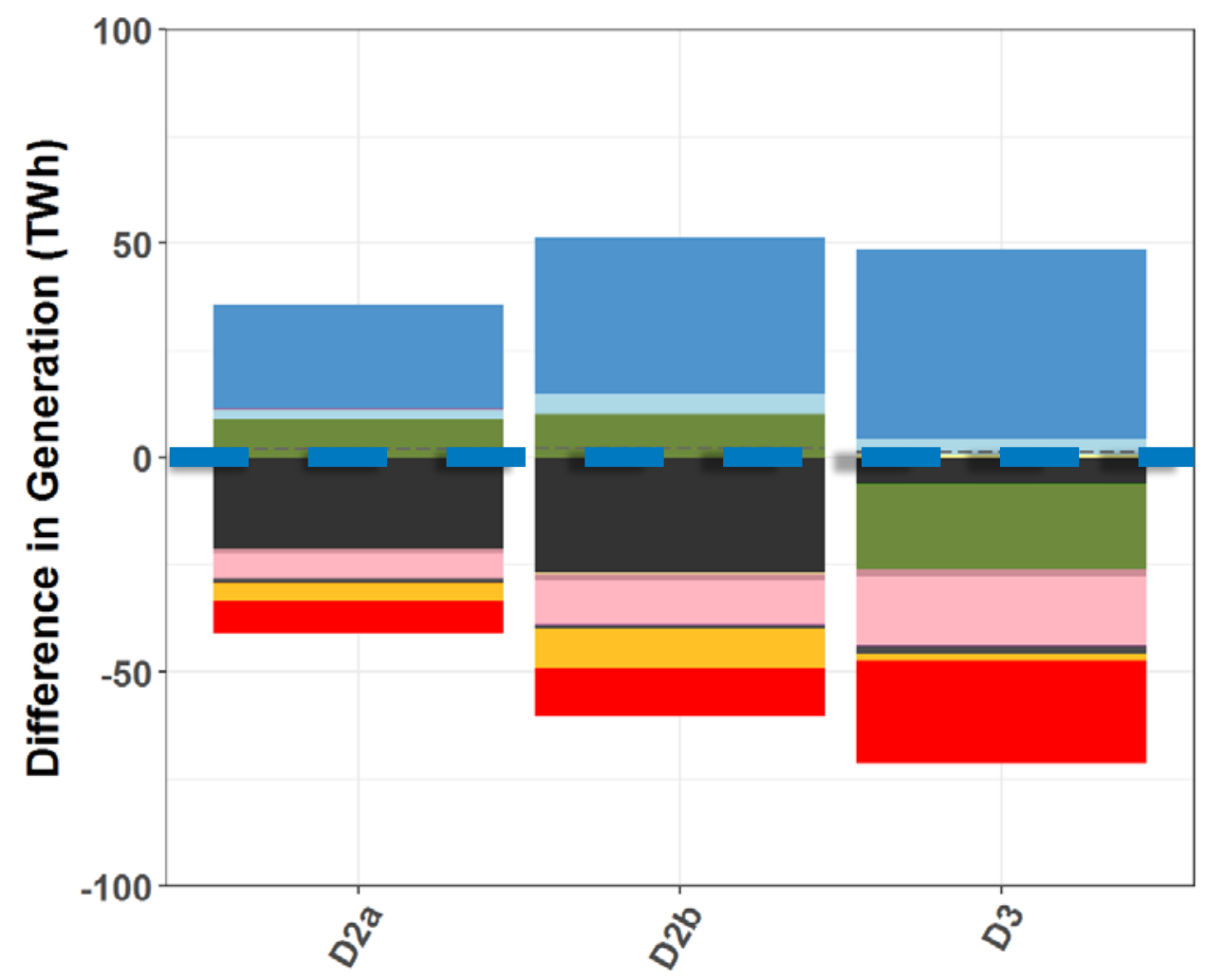

High VG

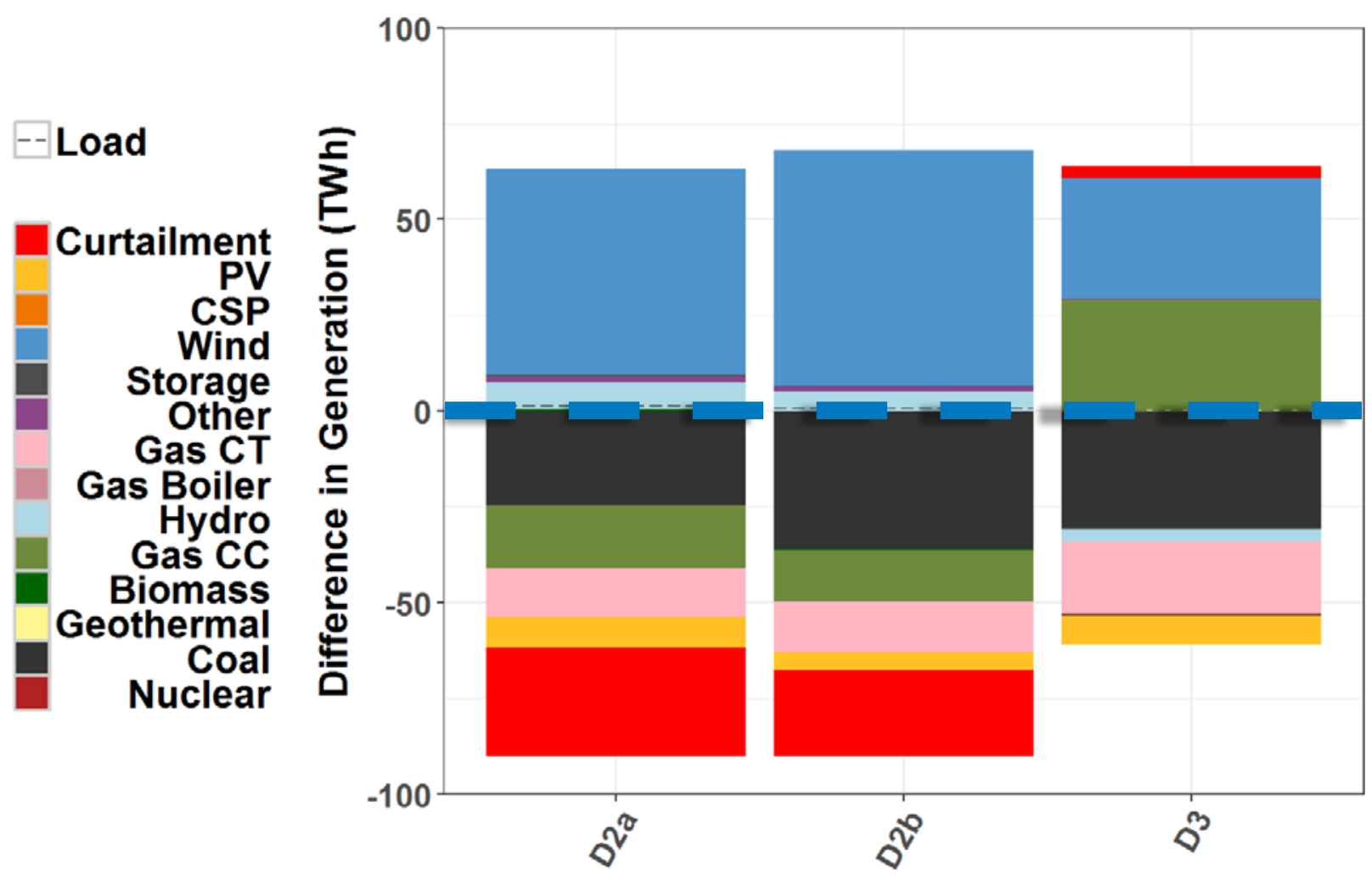




\section{What could it cost?}

\section{What are the benefits?}
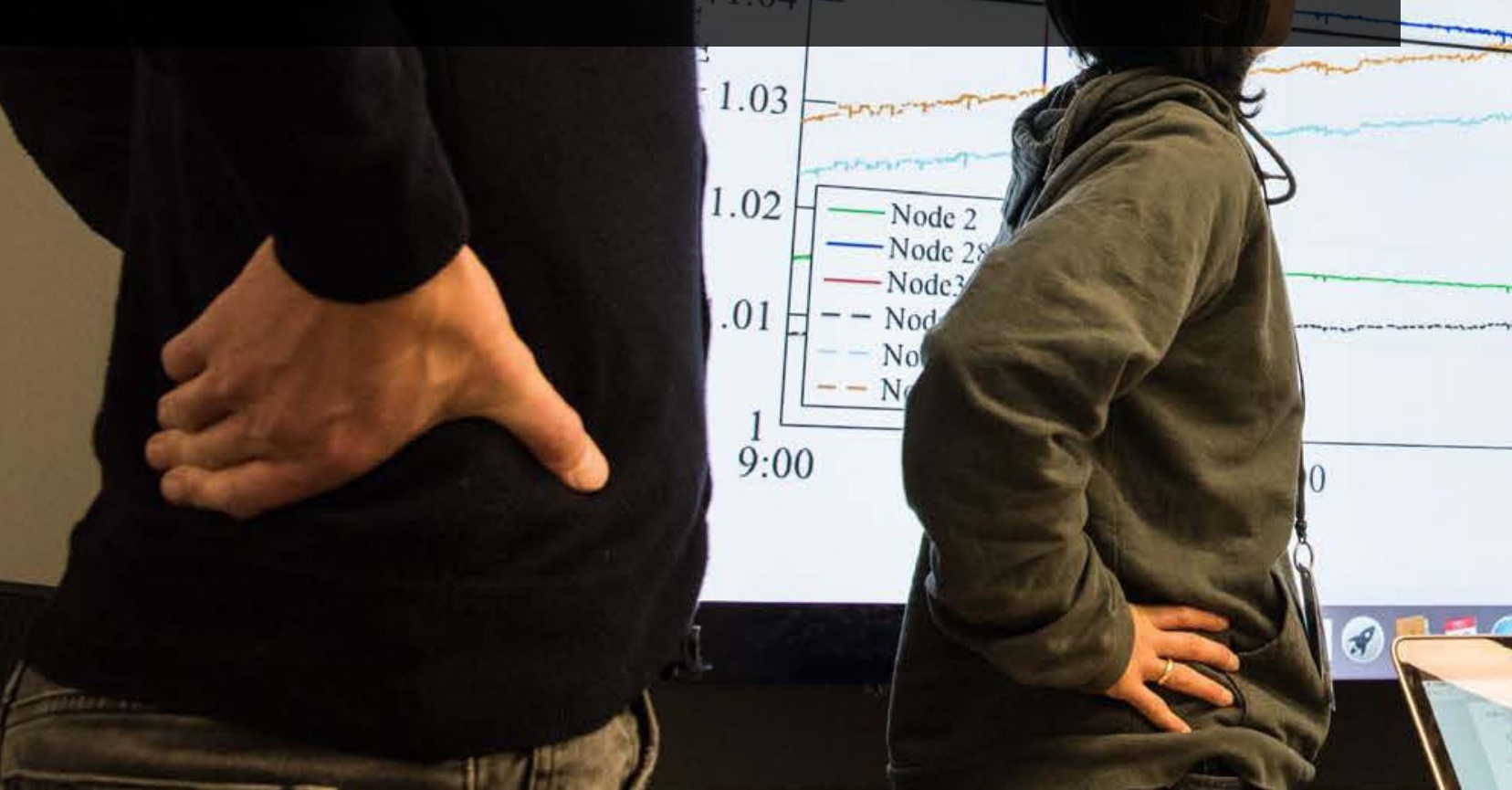
Net Cost Relative to Design 1

- Net cost (negative indicates savings) considers the difference in costs between each design and Design 1 for that scenario

\begin{tabular}{|l|c|c|c|}
\hline Scenario & $\boldsymbol{\Delta D 2 a}$ & $\mathbf{\Delta D 2 b}$ & $\boldsymbol{\Delta D 3}$ \\
\hline Base Case & -2.6 & -4.5 & -2.9 \\
\hline Low Gas Price & -2.9 & -4.2 & -2.4 \\
\hline High Gas Price & -4.7 & -9.5 & -5.9 \\
\hline $\begin{array}{l}\text { High AC Trx Cost } \\
(\mathbf{1 . 5 x})\end{array}$ & -2.2 & -5.4 & -4.6 \\
\hline High AC Trx Cost & & & \\
$(\mathbf{2 x})$ & -2.1 & -5.5 & -5.5 \\
\hline No retirements & -1.2 & -1.6 & -0.8 \\
\hline Low-cost & & & \\
renewables & -2.9 & -4.8 & -3.0 \\
\hline High VG & -18.3 & -28.8 & -23.0 \\
\hline
\end{tabular}




\section{Benefit-Cost Ratio}

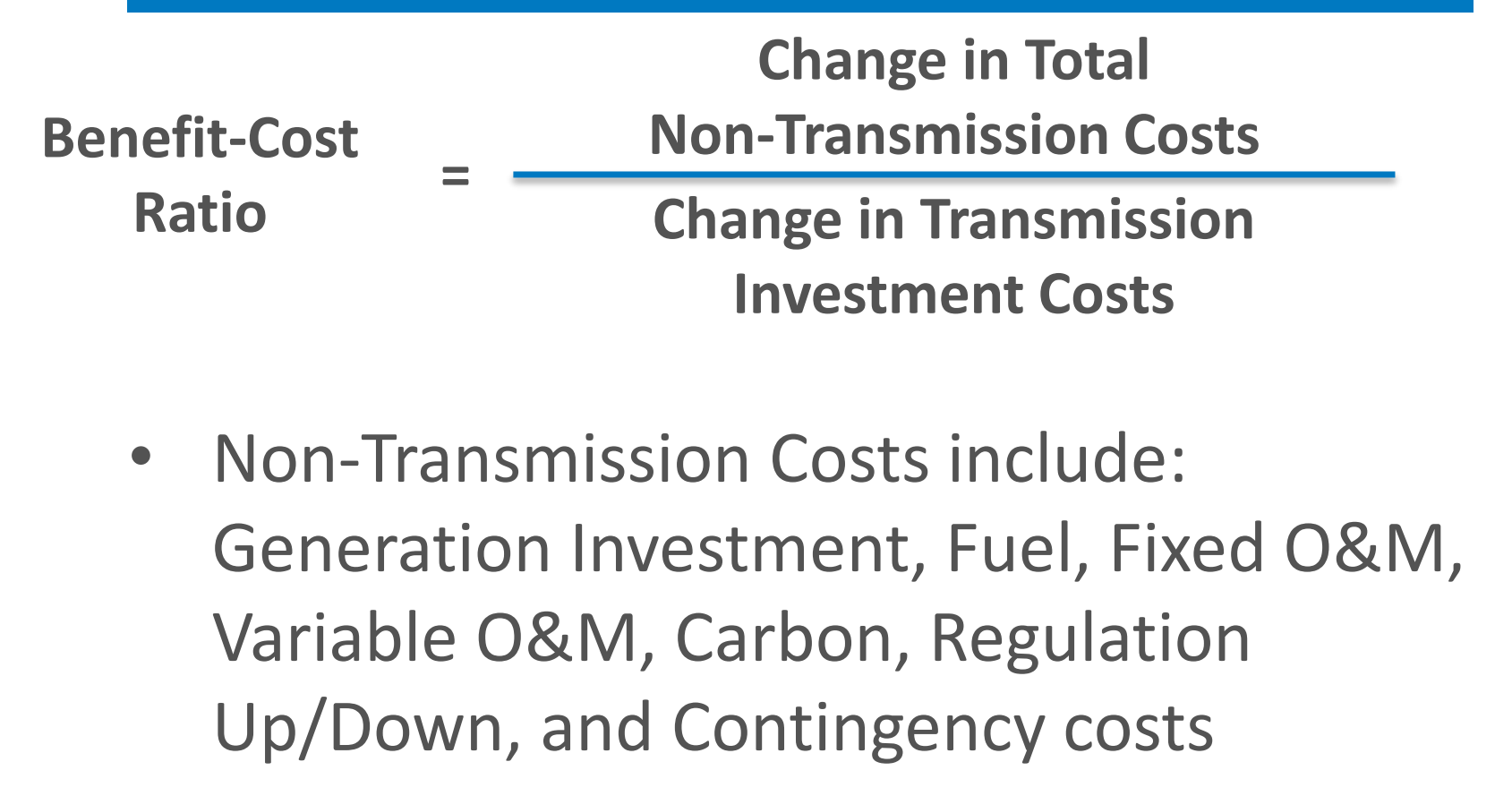

\begin{tabular}{|l|c|c|c|}
\hline Scenario & $\mathbf{\Delta D 2 a}$ & $\mathbf{\Delta D 2 b}$ & $\mathbf{\Delta D 3}$ \\
\hline Base Case & 2.02 & 1.66 & 1.36 \\
\hline Low Gas Price & 1.81 & 1.52 & 1.22 \\
\hline High Gas Price & 1.76 & 1.84 & 1.46 \\
\hline $\begin{array}{l}\text { High AC Trx Cost } \\
(\mathbf{1 . 5 x})\end{array}$ & 1.87 & 1.45 & 1.29 \\
\hline $\begin{array}{l}\text { High AC Trx Cost } \\
(\mathbf{2 x})\end{array}$ & 2.26 & 1.52 & 1.37 \\
\hline No retirements & 1.98 & 1.72 & 1.33 \\
\hline $\begin{array}{l}\text { Low-cost } \\
\text { renewables }\end{array}$ & 2.53 & 1.77 & 1.56 \\
\hline High VG & 2.09 & 2.89 & 1.80 \\
\hline
\end{tabular}




\section{Cost Breakdown}

\section{Summary of Benefit/Cost Results from CGT-Plan Model}

Base Scenario

\begin{tabular}{|l|r|r|r|r|}
\hline Capacity or Cost Item & \multicolumn{1}{|c|}{ D1 } & \multicolumn{1}{|c|}{ DD2a } & \multicolumn{1}{|c|}{ D2b } & \multicolumn{1}{c|}{$\boldsymbol{\Delta D 3}$} \\
\hline $\begin{array}{l}\text { Transmission } \\
\text { Investment Cost, \$B }\end{array}$ & 40.03 & 2.57 & 6.76 & 8.19 \\
\hline $\begin{array}{l}\text { Generation } \\
\text { Investment Cost, \$B }\end{array}$ & 555.23 & 3.6 & 10.44 & 4.17 \\
\hline Operational cost, \$B & 2376.50 & -8.79 & -21.70 & -15.30 \\
\hline $\begin{array}{l}\text { 35-yr Net Cost } \\
\text { change, \$B }\end{array}$ & - & -2.62 & -4.5 & -2.94 \\
\hline 35-yr B/C ratio & - & 2.02 & 1.66 & 1.36 \\
\hline
\end{tabular}

High VG Scenario

\begin{tabular}{|l|r|r|r|r|}
\hline Capacity or Cost Item & \multicolumn{1}{|c|}{$\mathbf{D 1}$} & \multicolumn{1}{|c|}{$\mathbf{\Delta D 2 a}$} & \multicolumn{1}{|c|}{$\mathbf{\Delta D 2 b}$} & \multicolumn{1}{c|}{$\boldsymbol{\Delta D 3}$} \\
\hline $\begin{array}{l}\text { Transmission } \\
\text { Investment Cost, \$B }\end{array}$ & 71.69 & 16.79 & 15.6 & 28.86 \\
\hline $\begin{array}{l}\text { Generation } \\
\text { Investment Cost, \$B }\end{array}$ & 741.38 & 6.83 & 8.02 & 7.95 \\
\hline Operational Cost, \$B & 2563.3 & -41.97 & -52.45 & -59.85 \\
\hline $\begin{array}{l}\text { 35-year Net Cost } \\
\text { change, \$B }\end{array}$ & NA & -18.35 & -28.83 & -23.04 \\
\hline 35-year B/C Ratio & NA & 2.09 & 2.89 & 1.80 \\
\hline
\end{tabular}




\section{Key Findings}

- The power system can balance generation and load.

- Additional transmission enabled lower total installed capacities, especially in the High VG scenario.

- There are substantial positive benefit-cost ratios for increasing the transfer capability between the interconnections.

- Cross-seam transmission has a substantial impact on the location of wind and solar generation additions.

- Wind shifts to the Eastern Interconnection and solar to the Western Interconnection.

- Additional benefits and costs may exist (e.g., frequency response and resilience to extreme events). 


\section{Caveats and Future Work}

- $\quad$ Caveats

- The study provides initial valuations of increasing transmission capacity between the interconnections, but it should not be referenced as reporting final ready-to-build designs.

- The study does not take the place of regional planning studies.

- The study does not obviate the need for state and federal siting review.

- The study does not consider the impact on wholesale rates set by the Federal Energy Regulatory Commission (FERC) or North American Electric Reliability Corporation (NERC) reliability standards under Federal Power Act Sections 203, 205, and 206.

- $\quad$ Potential Future Work

- Potential reliability and resilience assessment via AC power flow studies with steady-state and stability modeling

- Consideration of system resilience and security requirements related to weather and extreme conditions

- Evaluation of natural gas delivery infrastructure and gas-electric operational coordination. 


\section{Thank you}

\section{www.nrel.gov}

NREL/PR-6A20-78161

This work was authored in part by the National Renewable Energy Laboratory, operated by Alliance for Sustainable Energy, LLC, for the U.S. Department of Energy (DOE) under Contract No. DE-AC36-08G028308. Funding provided by the U.S. Department of Energy Office of Energy Efficiency and Renewable Energy Wind Energy Technologies Office and the Office of Electricity. As a Pioneer Regional Partnership project of DOE's Grid Modernization Initiative. The views expressed in the article do not necessarily represent the views of the DOE or the U.S. Government. The U.S. Government retains and the publisher, by accepting the article for publication, acknowledges that the U.S.

Government retains a nonexclusive, paid-up, irrevocable, worldwide license to publish or reproduce the published form of this work, or allow others to do so, for U.S. Government purposes.

BNREL

Transforming ENERGY 